\title{
A Psicopatia no Contexto dos Cinco Grandes Fatores da Personalidade
}

\author{
Renan Pereira Monteiro \\ Universidade Federal da Paraíba \\ João Pessoa, PB, Brasil \\ Rildésia Silva Veloso Gouveia \\ Centro Universitário de João Pessoa \\ João Pessoa, PB, Brasil \\ Christopher J. Patrick \\ Florida State University \\ Tallahassee, Flórida, EUA \\ Hudson W. de Carvalho \\ Universidade Federal de Pelotas \\ Pelotas, RS, Brasil \\ Emerson Diógenes Medeiros \\ Universidade Federal do Piaui \\ Parnaíba, PI, Brasil \\ Carlos Eduardo Pimentel \\ Valdiney Veloso Gouveia \\ Universidade Federal da Paraíba \\ João Pessoa, PB, Brasil
}

\begin{abstract}
RESUMO
A psicopatia configura-se como um grave transtorno da personalidade. Apesar de resultados indicarem a extroversão e amabilidade como dois dos marcadores dos big five como seus preditores, são escassas as evidências no Brasil. Portanto, este estudo objetivou conhecer em que medida os fatores de personalidade normal se correlacionam com os três fenótipos avaliados pela Medida Triádica de Psicopatia (TriPM). Participaram da pesquisa 228 estudantes universitários de João Pessoa (PB), apresentando idade média de 25,1 anos, a maioria do sexo feminino (76\%). Estes responderam a TriPM, o Inventário dos Cinco Grandes Fatores da Personalidade e perguntas demográficas. Os resultados indicaram que os fatores extroversão, abertura à mudança e amabilidade predisseram a psicopatia, corroborando estudos prévios. Estes achados são discutidos tomando como base o modelo dos big five para compreender este traço socialmente desviante, onde a ausência de afeto e o comportamento manipulador são características centrais.
\end{abstract}

Palavras-chave: Psicopatia; Big Five; Personalidade; Traço; Extroversão.

\section{ABSTRACT}

\section{Psychopathy in the Context of the Big Five Personality Factors}

Psychopathy is a severe personality disorder. Despite results indicating that extraversion and agreeableness are two markers of the big five as its predictors, evidence in Brazil are limited. Therefore, this study aimed to know whether normal personality (non-psychotic) factors predict the three phenotypes evaluated by the Triarchic Psychopathy Measure (TriPM). Participants were 228 undergraduate students from João Pessoa (PB), with mean age of 25.1 years, mostly were female (76\%). They answered the TriPM, the Big Five Inventory, and demographic questions. Results indicated that the factors extraversion, openness to experience and agreeableness predicted psychopathy, which corroborated previous studies. These findings are discussed on the basis of the big five model in order to understand this socially deviant trait, in which the lack of affection and the manipulative behavior are central features.

Keywords: Psychopathy; Big Five; Personality; Trait; Extraversion.

\section{RESUMEN}

Psicopatía en el Contexto de los Cinco Grandes Factores de Personalidad

La psicopatía se configura como un transtorno grave de la personalidad. Aunque los estudios indican extraversión y amabilidad como dos de los cinco marcadores como sus predictores, se ha observado poca evidencia en Brasil. Por lo tanto, este estudio tuvo como objetivo conocer en qué medida los factores de la personalidad normal se correlacionan con fenotipos contemplados por la Medida Triádica de Psicopatía (TriPM). Los participantes han sido 228 universitarios de João Pessoa (PB), con una edad promedia de 25.1 años, en mayoría mujeres (76\%). Éstos contestaron la TriPM, Inventario de los Cinco Grandes Factores de Personalidad y preguntas demográficas. Los resultados indicaron que los factores extraversión, apertura a la experiencia y amabilidad se asociaron con la psicopatía, corroborando estudios previos. Se discuten estos hallazgos según el modelo de los cinco grandes, poniendo énfasis en ese rasgo socialmente desviante, caracterizado por la falta de afecto y la conducta manipuladora.

Palabras clave: Psicopatía; Cinco Grandes; Personalidad; Rasgo; Extraversión. 


\section{INTRODUÇÃO}

O estudo da psicopatia tem se mostrado um tema de interesse de longa data para as ciências do comportamento por razões de relevância teórica e social. Concepções contemporâneas sobre o referido construto delimitam perfis caracterizados por déficits de controle inibitório e de reatividade emocional (Fowles \& Dindo, 2006; Likken, 2006), o que deflagra um contexto privilegiado para o estudo de processos psicobiológicos básicos relativos a regulação emocional e do comportamento. Indivíduos identificados como psicopatas apresentam maior frequência de conduta antissocial que a população geral, além de responderem por uma quantidade maior de crimes violentos dentre aqueles que se encontram em situação prisional (Potter \& Woodworth, 2006).

Historicamente, verificam-se alguns precursores no estudo do que hoje se entende por psicopatia. Cabe destacar que os conceitos iniciais eram generalistas, buscando descrever quadros de insanidade, abrangendo categoriais distintas o que impossibilita comparações com o atual entendimento em torno da psicopatia. Nesta direção, ao se apresentar um breve histórico, objetiva-se ter em conta como o conceito evoluiu ao longo dos anos. No que tange a produção acadêmica sobre a psicopatia, Patrick, Fowles e Krueger (2009) a organizam em quatro momentos distintos. Os primeiros conceitos, precursores da psicopatia, a delimitavam como uma síndrome localizada no indivíduo que o predisporia ao comportamento antissocial, impulsivo, raivoso, agressivo e ao uso nocivo de substâncias. Tais tendências psicológicas não poderiam ser concomitantes com alterações da consciência e do pensamento. Contemporaneamente, essa perspectiva é mais próxima do conceito de espectro de externalização: uma tendência geral ao comportamento antissocial, à impulsividade e ao uso nocivo de substâncias (Carvalho, Jorge, \& Lara, 2014; Krueger, Markon, Patrick, \& Iacono, 2005).

A segunda leva de estudos que antecederam a moderna concepção sobre psicopatia foram influenciados pela taxonomia de Kraepelin (1904), caracterizando pessoas com histórico de fraudes e estelionato, que mostravam alta habilidade de persuasão e ausência ou fragilidade de princípios morais elementares. Outras descrições desse período que repercutiram historicamente no estudo da psicopatia delimitavam um perfil de pessoas egocêntricas, superficiais, charmosas e com reações emocionais levianas em relação aos outros (Patrick et al., 2009). Em relação a perspectiva anterior, houve uma alternância de foco: de condutas delitivas explícitas para domínios psicológicos e interpessoais implícitos. A terceira vertente de estudos, baseados em relatos clínicos de Pinel (1962), descrevia alguns aspectos que são tidos em conta na concepção atual de psicopatia, como apresentar um estilo de vida produtivo e compatível com as expectativas sociais, mas com a existência de um déficit central no processamento emocional que impossibilitaria a manifestação de uma postura empática e prossocial autêntica, assim como relacionamentos afetivos genuínos.

Em grande medida, a quarta e atual ênfase de estudos constitui seu objeto de investigação no tratado clássico de Cleckley (1976) sobre psicopatia, The Mask of Sanity (A Máscara da Sanidade). Cleckley baseado na avaliação clínica de 15 pacientes internados, dissociou o construto psicopatia dos indicadores de conduta antissocial e delitiva, configurando-o como uma condição neuropsiquiátrica que, apesar de apresentar uma fenomenologia que poderia mimetizar a expectativa de normalidade, é caracterizada por déficits emocionais e interpessoais que abalizariam um caráter pautado por insensibilidade interpessoal, egocentrismo, impessoalidade, baixa reatividade emocional e empatia. A fim de criar subsídios operacionais para orientar a avaliação clínica, Cleckley proveu uma lista de 16 indicadores que podem ser organizados em três grupos (Patrick et al., 2009): (1) ajustamento positivo, caracterizado por um funcionamento intelectual e psicossocial comparável ao da população geral; (2) comportamento disruptivo, marcado por irresponsabilidade, promiscuidade sexual, conduta antissocial e falta de planejamento para a vida e (3) déficits emocionais e interpessoais, talhados por pobreza emocional, ausência de culpa e remorso, baixa empatia e elevado egocentrismo. Tais critérios serviram e ainda servem de base para a definição constitutiva e psicodiagnóstico da psicopatia.

Os indicadores diagnósticos providos por Cleckley (1976) possibilitaram o desenvolvimento de instrumentos objetivos que, por sua vez, fomentaram uma profusão de estudos empíricos sobre o construto (Patrick, 2006). Todavia, os instrumentos disponíveis para avaliação clínica ou psicométrica da psicopatia apresentam limitações de escopo e/ou relacionados à validade de construto. O Psychopathy ChecklistRevised(PCL-R; Hare, 2003), por exemplo, é o principal instrumento utilizado para a avaliação de psicopatia em amostras de infratores e desenha a psicopatia como um fenômeno unitário conformado a partir de dois fatores: o primeiro avalia aspectos emocionais-interpessoais e o segundo conduta disruptiva. Destacam-se divergências quanto a estrutura fatorial desta medida, contudo, uma revisão sistemática recente mostrou um número maior de estudos que apoiam a estrutura bifatorial (Hauck Filho, Teixeira, \& Almeida, 2014). Devido o foco na 
avaliação de indivíduos em situação prisional, os itens abarcam os indicadores de comportamento disruptivo e déficit emocional descritos por Cleckley (1976), porém não avaliam os elementos relacionados ao ajustamento positivo. Além disso, apesar do conjunto de evidências indicar que a psicopatia é um fenômeno multifatorial, o PCL-R trabalha com a concepção do fenômeno unitário (Patrick et al., 2009).

Outra medida para estimar traços da psicopatia é o Psychopathic Personality Inventory (PPI; Lilienfeld $\&$ Widows, 2005). Este é um instrumento amplamente usado para a avaliação da psicopatia na população geral e - apesar de avaliar o construto sob uma ótica multifatorial - seu espectro de conteúdo falha em abordar de modo equânime alguns domínios, deixando hiporrepresentados elementos interpessoais importantes como a empatia e a crueldade.

Mantendo em perspectiva as referidas limitações, Patrick et al. (2009) propuseram uma perspectiva integrativa e multidimensional denominado de Modelo Triádico da Psicopatia (MTP). Esse modelo pretendeu prover uma visão teórica e operacional abrangente do construto, o que possibilitaria a sua avaliação em indivíduos infratores e não infratores, com tendências mais estáveis ou explosivas, adolescentes ou adultos e com ou sem sucesso em se adaptar aos padrões sociais desejáveis (psicopatas bem sucedidos). O MTP define a psicopatia como um fenômeno complexo erigido a partir da interação de três dimensões independentes de desinibição (disinhibition), audácia (boldness) e crueldade (meanness).

Desinibição descreve a extensão na qual uma pessoa é impulsiva, imprudente, tolerante à frustração (Patrick et al., 2009). Esses traços se assemelham ao conceito de externalização (Carvalho, Patrick, Krueger, Markon, \& Pinheiro, 2010; Krueger et al., 2005), uma dimensão que explica as associações entre controle de impulsos, uso nocivo de substâncias e conduta antissocial. Audácia descreve o grau em que alguém é resistente à pressão interpessoal e ambiental, assim como o quão rápido se recupera de situações potencialmente traumáticas e o quanto é capaz de manter calma diante do desconhecido e do perigo. Essa dimensão aborda aspectos positivos/adaptativos no contexto da psicopatia. Por fim, a dimensão de Crueldade descreve atributos que envolvem tendências para a insensibilidade, falta de empatia e solidariedade, incapacidade de estabelecer laços afetivos duradouros, reações emocionais superficiais, estilo de vida parasita, formas instrumentais ou predatórias de agressão, rebeldia e busca de sensações.

Os três domínios descritos foram operacionalizados pela Medida Triádica da Psicopatia (Triarchic
Psychopathy Measure, TriPM; Patrick, 2010), um questionário de autorrelato de 58 itens que avaliam as dimensões de desinibição (20 itens), audácia (19 itens) e crueldade (19 itens) por meio de uma escala likert de quatro pontos. Quanto aos parâmetros psicométricos, são consistentes as evidências em torno da validade e precisão desta medida. Por exemplo, estudos vem indicando que a TriPM apresenta evidências de validade convergente com outras medidas mais conhecidas de psicopatia (e.g., Levenson Self-Report Psychopathy, PPI e Self-Report Psychopathy; Drislane, Patrick, \& Arsal, 2014; Stanley, Wygant, \& Sellbom, 2013).

Quanto a consistência interna, observa-se que os fatores da TriPM vem mostrando indicadores aceitáveis. Por exemplo, Stantey et al. (2013) encontraram alfas variando de 0,77 (audácia) a 0,88 (crueldade). Maiores evidências da precisão das subescalas da TriPM são disponibilizadas por Sellbom e Phillips (2013), que, considerando amostras de presidiárias e universitários, encontraram, para a primeira amostra, alfas variando de 0,89 (audácia e desinibição) a 0,90 (crueldade) e de 0,82 (audácia) a 0,88 (crueldade) para a segunda. Em outro estudo, Blagov, Patrick, Oost, Goodman e Pugh (2015) corroboraram este parâmetro psicométrico da TriPM, com alfas variando de 0,80 (audácia e desinibição) a 0,87 (crueldade). Ademais, testaram a estabilidade temporal da medida, sendo que depois de três meses as escalas apresentaram correlações entre 0,67 a 0,77 . Portanto, a TriPM tem se mostrado um instrumento heurístico para pesquisa sobre psicopatia.

Considerando estudos com medidas de psicopatia, são frequentes aqueles que buscam evidências de validade com base nas correlações com modelos gerais da personalidade (e.g., Lynam \& Miller, 2014; Miller, Hyatt, Rauscher, Maples, \& Zeichner, 2014). Nesta direção, no tópico a seguir, serão discutidas as relações entre as dimensões da psicopatia e os cinco grandes fatores da personalidade, trazendo alguns estudos que reuniram evidências de validade da TriPM com base nas correlações com os big five.

\section{Traços normais da personalidade e psicopatia}

Conforme apresentado, tanto em termos conceituais (MTP) quanto operacionais (TriPM), o construto psicopatia é definido a partir de traços específicos da personalidade que pretendem avaliar um amplo espectro das diferenças individuais. Dada a relevância social e teórica do construto, entender como essas dimensões se articulam com modelos gerais da personalidade pode ser relevante na medida em que possibilita compreender o contínuo normalpatológico. Atualmente, o Modelo dos Cinco Grandes Fatores da Personalidade (CGF) constitui-se como um 
dos mais utilizados para o entendimento da estrutura da personalidade.

McCrae e John (1992) descrevem o CGF como uma organização hierárquica dos traços de personalidade, dispostos em cinco grandes dimensões que fornecem uma estrutura na qual a maioria dos traços pode ser classificada (McRae, 2010). No Brasil, tais fatores vêm sendo nomeados de extroversão, neuroticismo (instabilidade emocional), amabilidade (agradabilidade, sociabilidade ou cordialidade), conscienciosidade (escrupulosidade) e abertura à mudança ou experiência (Silva \& Nakano, 2011).

Cada dimensão avalia com independência diferentes tendências individuais. Extroversão se refere ao grau de socialização, energia, emocionalidade positiva e busca de sensações. Neuroticismo é uma dimensão geral que explica as associações entre emocionalidade negativa e instabilidade emocional. Amabilidade descreve o quanto alguém é cordial, empático, solidário e abnegado. Conscienciosidade concerne às tendências individuais relacionados ao autocontrole, pontualidade, precisão e diligência. Abertura à mudança explica as diferenças individuais em relação ao interesse pela cultura, estética, criatividade e flexibilidade cognitiva.

Com base no CGF, a psicopatia tem sido sistematicamente descrita como confluência de baixos escores nos fatores de Amabilidade e Conscienciosidade. Este entendimento tem sido corroborado mesmo em pesquisas que apresentam heterogeneidade metodológica (Decuyper, De Pauw, De Fruyt, De Bolle, \& De Clercq, 2009; Lynam \& Derefinko, 2006). Entretanto, há resultados que mostram certa divergência: por exemplo, o indicador de conduta disruptiva do PCL-R (Hare, 2004) mostra correlações significativas e positivas com neuroticismo (Lynam \& Widiger, 2007) já o fator emocional-interpessoal também parece apresentar associações negativas com extroversão e abertura à mudança (Miller, Watts, \& Jones, 2011).

Considerando a pertinência de estimar a psicopatia a partir de traços gerais da personalidade, pesquisadores tem buscado reunir evidências de validade da TriPM a partir das correlações com o CGF. Atentando para isso, Stanley et al. (2013), considerando uma amostra carcerária, verificaram que audácia predisse extroversão $(\beta=0,46)$, neuroticismo $(\beta=-0,44)$, abertura à mudança ( $\beta=0,31)$ e conscienciosidade $(\beta=0,26)$, crueldade foi preditor de amabilidade $(\beta=-0,55)$, conscienciosidade $(\beta=-0,38)$ e abertura à mudança $(\beta=-0,31)$, e, por fim, desinibição predisse neuroticismo $(\beta=0,35)$ e conscienciosidade $(\beta=-0,31)$.

Poy, Segarra, Esteller, López e Moltó (2014) também buscaram conhecer em que medida os três fatores da TriPM se correlacionam com os fatores e facetas do CGF. No caso, tais autores verificaram um padrão complexo de associações, porém condizente com as definições dos construtos. Audácia apresentou correlação moderada e negativa com neuroticismo $(r \cong-0,6)$, moderada e positiva com extroversão $(r \cong 0,6)$ e abertura $(r \cong 0,4)$ e não significante com amabilidade $(r \cong 0,1)$ e conscienciosidade $(r \cong-0,1)$. Crueldade apresentou associações negligenciáveis com neuroticismo, extroversão e abertura e negativas com conscienciosidade $(r \cong-0,3)$ e amabilidade $(r \cong-0,6)$, de modo que os coeficientes entre Crueldade e amabilidade foram mais elevados na amostra masculina $(r=-0,7)$ que na feminina $(r=-0,45)$. Desinibição apresentou associação moderada com neuroticismo $(r \cong 0,4)$, amabilidade $(r \cong-0,4)$ e conscienciosidade $(r \cong-0,5)$.

Blagov et al. (2015) também buscaram estimar em que medida os três fatores da TriPM se correlacionam com o CGF. Controlando as dimensões crueldade e desinibição, os autores verificaram que audácia correlacionou-se fortemente com extroversão $(r=0,66)$ e neuroticismo $(r=-0,66)$. Desinibição, quando as outras dimensões foram controladas, correlacionou-se apenas com conscienciosidade $(r=-0,43)$. E, por fim, verificou-se que crueldade apresentou correlações com amabilidade $(r=-0,57)$, extroversão $(r=-0,32)$ e abertura à mudança $(r=-0,30)$, quando se controlou os demais fatores. Logo, os resultados reportados indicam que os três domínios fenotípicos da psicopatia (Audácia, Desinibição e Crueldade) apresentam configurações distintas com relação aos cinco grandes fatores da personalidade.

Percebe-se, portanto, a importância de conhecer em que medida os traços psicopáticos se relacionam com os cinco grandes fatores da personalidade, aumentando o entendimento sobre o transtorno e trazendo maiores evidências em torno da pertinência do modelo CGF para o entendimento de psicopatologias. Ademais, considerando a relevância de estimar traços psicopáticos, bem como as críticas associadas as medidas mais empregadas, é fundamental buscar formas mais integradoras e que cubram, de forma equânime, os domínios da psicopatia.

Nesta direção, optou-se por traduzir para o português brasileiro a TriPM. Por ser uma medida recente, a principal lacuna que se percebe é a falta de validação transcultural, o que exige que se disponha de distintas versões em variadas línguas. O presente estudo buscou contribuir com uma versão para o português brasileiro, posto que, até o presente momento, não foi encontrada qualquer versão traduzida para o contexto brasileiro, algo que impossibilita a realização de estudos empíricos que tenham em conta esta medida e a verificação de seus correlatos. Inclusive, há a possibilidade de se constatar que os correlatos da psicopatia independem 
da medida utilizada, minimizando a fonte de variância decorrente do instrumento.

Considerando os aspectos previamente expostos, o presente estudo apresenta dois objetivos associados: primeiro, descrevemos o procedimento adotado para adaptar a TriPM para o português brasileiro e, subsequentemente, verificamos a relação entre os domínios avaliados por essa versão da TriPM com uma medida dos cinco grandes fatores da personalidade. Ao final, discutimos as implicações dos resultados para o MTP e para a versão adaptada da TriPM. As hipóteses iniciais foram: (1) Audácia apresentará uma configuração mais adaptativa de personalidade, caracterizada por uma correlação negativa com neuroticismo e positiva com extroversão e abertura à mudança; (2) Desinibição uma configuração mais desadaptativa de personalidade marcada por correlações positivas com neuroticismo e negativas com conscienciosidade e amabilidade e, por fim, (3) Crueldade apresentará correlações negativas com amabilidade.

\section{MÉTODO}

\section{Adaptação da TriPM para o português brasileiro}

As escalas de Desinibição e Crueldade do TriPM foram delineadas a partir de 39 itens desenhados para avaliar diferentes facetas da Externalização, medidas pelo Inventário Espectral de Externalização (IEE; Krueger, Markon, Patrick, Benning, \& Kramer, 2007). Este, por sua vez, passou por procedimentos de adaptação linguística para o português brasileiro (Carvalho, Pinheiro, Patrick, Krueger, \& Markon, 2007) e validação fatorial em uma amostra de universitários brasileiros (Carvalho et al., 2010). Assim sendo, 39 itens foram extraídos diretamente do IEE, sem que houvesse necessidade de adaptações adicionais. O restante dos itens foram traduzidos e adaptados pelos autores deste manuscrito, passando por um procedimento de tradução reversa (do português para o inglês) por um linguista e enviado para o autor da TriPM, cujos pareceres possibilitaram o seu aperfeiçoamento. Esse processo foi repetido duas vezes até que se alcançasse concordância quanto ao formato ideal dos itens.

\section{TriPM: consistência interna e associações com os cinco grandes fatores da personalidade}

\section{Participantes}

Contou-se com uma amostra não probabilística de 228 estudantes universitários de instituições públicas e particulares da cidade de João Pessoa (PB). Estes apresentaram idades que variaram de 18 a 61 anos
$(M=25,1 ; D P=7,51)$, sendo a maioria do sexo feminino $(76 \%)$ e solteira $(76 \%)$.

\section{Procedimento}

Inicialmente, entrou-se em contato com as coordenações dos cursos das universidades selecionadas, solicitando a autorização para aplicação dos questionários. Posteriormente, com o consentimento dos professores, foram agendadas as coletas de dados, realizadas em ambiente coletivo de sala de aula, porém as respostas foram dadas individualmente. Assegurou-se o anonimato dos participantes, destacando que os dados seriam tratados em conjunto, bem como foi informado o caráter voluntário do estudo, podendo o participante desistir em qualquer etapa da pesquisa sem qualquer ônus. Todos precisaram preencher o Termo de Consentimento Livre e Esclarecido, de acordo com as recomendações éticas relacionadas às pesquisas com seres humanos, tendo o projeto sido previamente aprovado pelo Comitê de Ética em Pesquisa - Plataforma Brasil (Parecer no 383.319/2013). Na administração dos questionários, sempre estiveram presente dois colaboradores com intuito de dirimir possíveis dúvidas dos partícipes. O preenchimento dos instrumentos levou aproximadamente 20 minutos.

\section{Instrumentos}

TriPM: Questionário elaborado por Patrick (2010) visando mensurar os traços psicopáticos na população geral. Esta medida é composta por 58 itens, distribuídos nas três dimensões teorizadas (audácia, crueldade e desinibição), respondidos em escala tipo likert de quatro pontos $(1=$ Verdadeiro, $2=U m$ pouco verdadeiro, $3=$ Um pouco falso e $4=$ Falso), onde os participantes são orientados a indicar em que medida cada um dos itens o descreve.

Inventário dos Cinco Grandes Fatores (ICGF). Esta medida foi elaborada por John, Donahue e Kentle (1991) composta por 44 itens. Resultados sobre sua adaptação brasileira podem ser observados em Andrade (2008), cujos fatores apresentaram evidências de consistência interna, com alfas que variam de 0,68 (Abertura e Conscienciosidade) a 0,76 (Extroversão). Não obstante, optou-se por uma versão reduzida do ICGF, composta por 20 itens, tendo sido escolhidos os quatro com maiores cargas fatoriais no estudo de Schmitt et al. (2007). Os itens são estruturados em sentenças (e.g., Gosta de cooperar com os outros; É amável, tem consideração pelos outros), sendo o indivíduo solicitado a indicar como se percebe (Eu me vejo como alguém que...), utilizando escala tipo likert de cinco pontos, com os seguintes extremos: $1=$ Discordo totalmente e $5=$ Concordo totalmente . 


\section{Análise de dados}

Os dados foram analisados com o programa estatístico PASW (versão 18). A consistência interna foi estimada por meio do cálculo do coeficiente alfa separadamente para cada fator da TriPM. Calcularam-se, ainda, estatísticas descritivas, análise de correlação $r$ de Pearson e regressão linear múltipla (método stepwise), objetivando conhecer os traços de personalidade preditores da psicopatia. Por fim, realizou-se um escalonamento multidimensional com a meta de conhecer como os fatores da personalidade e os de psicopatia se distribuem em um espaço bidimensional.

\section{RESULTADOS}

Inicialmente, checou-se a consistência interna de cada subescala da TriPM, sendo que os resultados atestaram a confiabilidade dos fatores: audácia $(\alpha=0,75)$, crueldade $(\alpha=0,82)$ e desinibição $(\alpha=0,77)$. Posteriormente, computaram-se as pontuações para os três fatores da TriPM e sua pontuação total, isto é, somando todos os 58 itens. No caso dos cinco grandes fatores de personalidade, unicamente as pontuações totais para cada traço foi computada. Em seguida, correlacionaram-se as pontuações de psicopatia com aquelas de personalidade, sendo os resultados mostrados na Tabela 1.

Como mostrado na Tabela 1 , o escore total de psicopatia apresentou correlações com extroversão, abertura e amabilidade. Quando consideradas separadamente as dimensões da psicopatia, observase que audácia se correlacionou positivamente com extroversão, abertura e conscienciosidade e negativamente com neuroticismo. Crueldade se correlacionou inversamente com o traço amabilidade; enquanto desinibição se correlacionou positivamente com o traço neuroticismo e negativamente com conscienciosidade e amabilidade.

Conhecidas as correlações das dimensões de psicopatia com os traços de personalidade, decidiu-se realizar regressões lineares múltiplas (tipo stepwise), objetivando conhecer que traços predizem tais dimensões, incluindo a pontuação total de psicopatia. Tais resultados podem ser visualizados na Figura 1.

TABELA 1

Correlações entre as pontuações de psicopatia e dos big five

\begin{tabular}{lcccc}
\hline \multirow{2}{*}{ Big Five } & \multicolumn{4}{c}{ Fatores de Psicopatia } \\
\cline { 2 - 4 } & Total & Audácia & Crueldade & Desinibição \\
\hline Abertura & $0,21^{* *}$ & $0,36^{* *}$ & $-0,02$ & 0,00 \\
Conscienciosidade & 0,00 & $0,22^{* *}$ & $-0,11$ & $-0,20^{* *}$ \\
Extroversão & $0,24^{* *}$ & $0,39^{* *}$ & 0,00 & 0,08 \\
Amabilidade & $-0,17^{*}$ & 0,11 & $-0,37^{* *}$ & $-0,18^{* *}$ \\
Neuroticismo & 0,02 & $-0,34^{* *}$ & 0,12 & $0,35^{* *}$ \\
\hline
\end{tabular}

$* p<0,05, * * p<0,001$ (teste bi-caudal).

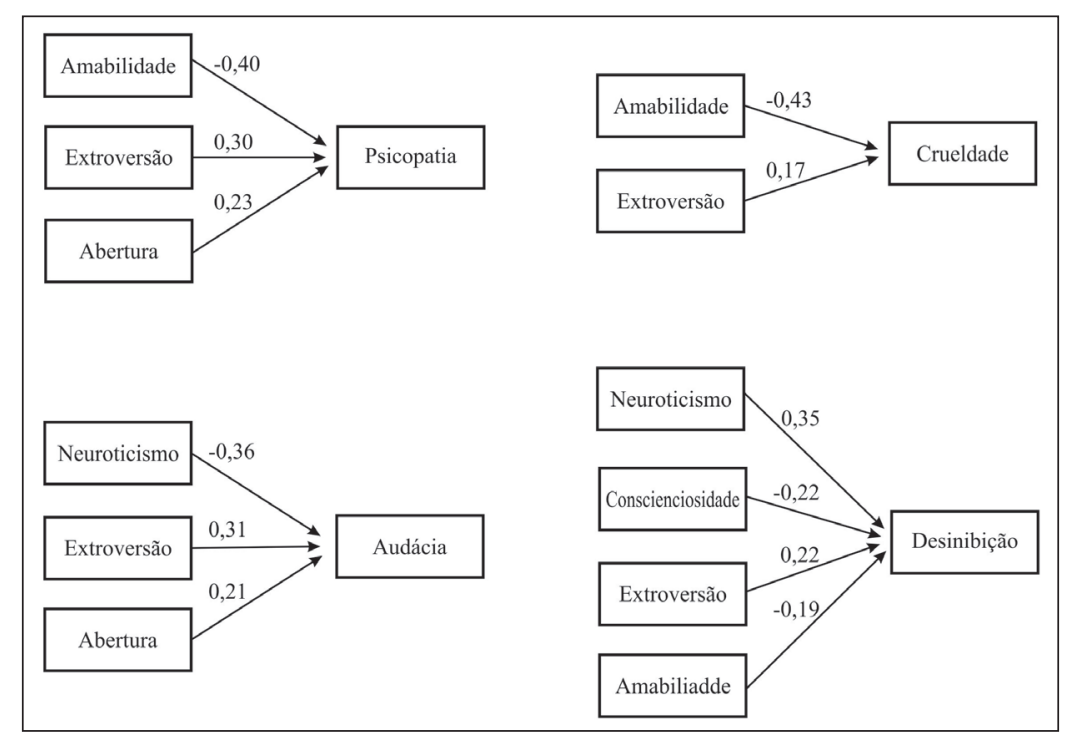

Figura 1. Representação gráfica das análises de regressão 
Neste caso, identificaram-se três fatores de personalidade como preditores da psicopatia $[R=0,44$, $\left.R^{2}=0,19, F(3,195)=15,48, p<0,001\right]:$ amabilidade, extroversão e abertura. Especificamente, a dimensão audácia foi predita por três traços de personalidade $\left[R=0,57, R^{2}=0,32, F(3,210)=33,48, \quad p<0,001\right]$ : neuroticismo, extroversão e abertura; crueldade foi predito por dois fatores da personalidade $[R=0,40$, $\left.R^{2}=0,16, F(2,213)=20,19, p<0,001\right]$ : amabilidade $\mathrm{e}$ extroversão; e, finalmente, desinibição foi predita por quatro traços $\left[R=0,47, R^{2}=0,22, F(4,209)=14,74\right.$, $p<0,001]$ : neuroticismo, conscienciosidade, extroversão e amabilidade.

A fim de buscar um entendimento da dinâmica subjacente de determinados traços de personalidade e fenótipos da psicopatia, decidiu-se representar espacialmente as pontuações destes dois construtos, por meio de uma análise de escalonamento multidimensional (Proxscal). Para tanto, criaram-se pontuações $\mathrm{z}$ entre as variáveis, resultando em distâncias euclidianas (escala intervalar), adotando-se a confi- guração inicial (método) de Torgerson. Os resultados são mostrados na Figura 2.

Os indicadores de ajuste permitem apoiar a representação desses construtos em um espaço bidimensional (Normalized Raw Stress $=0,01, S$-Stress $=0,02$ e Dispersion Accounted For =0,99). De acordo com esta figura, percebe-se a separação dos fatores de personalidade, que estão situados na parte inferior da Figura 1 e as dimensões de psicopatia, que concentramse na parte superior. Em termos de atributos mais diferenciadores, a amabilidade e a crueldade, respectivamente, apresentam-se como centrais para estes construtos, opondo-se claramente. Cabe destacar, também, a oposição entre audácia e neuroticismo, indicando que esta diferenciação é relevante na compreensão do construto. Existem elementos de um e outro que convergem mais, a exemplo da audácia com a abertura e a extroversão, que podem assinalar elementos socialmente aceitáveis. Por fim, destaca-se o isolamento do fator neuroticismo, que ficou mais próximo de desinibição.

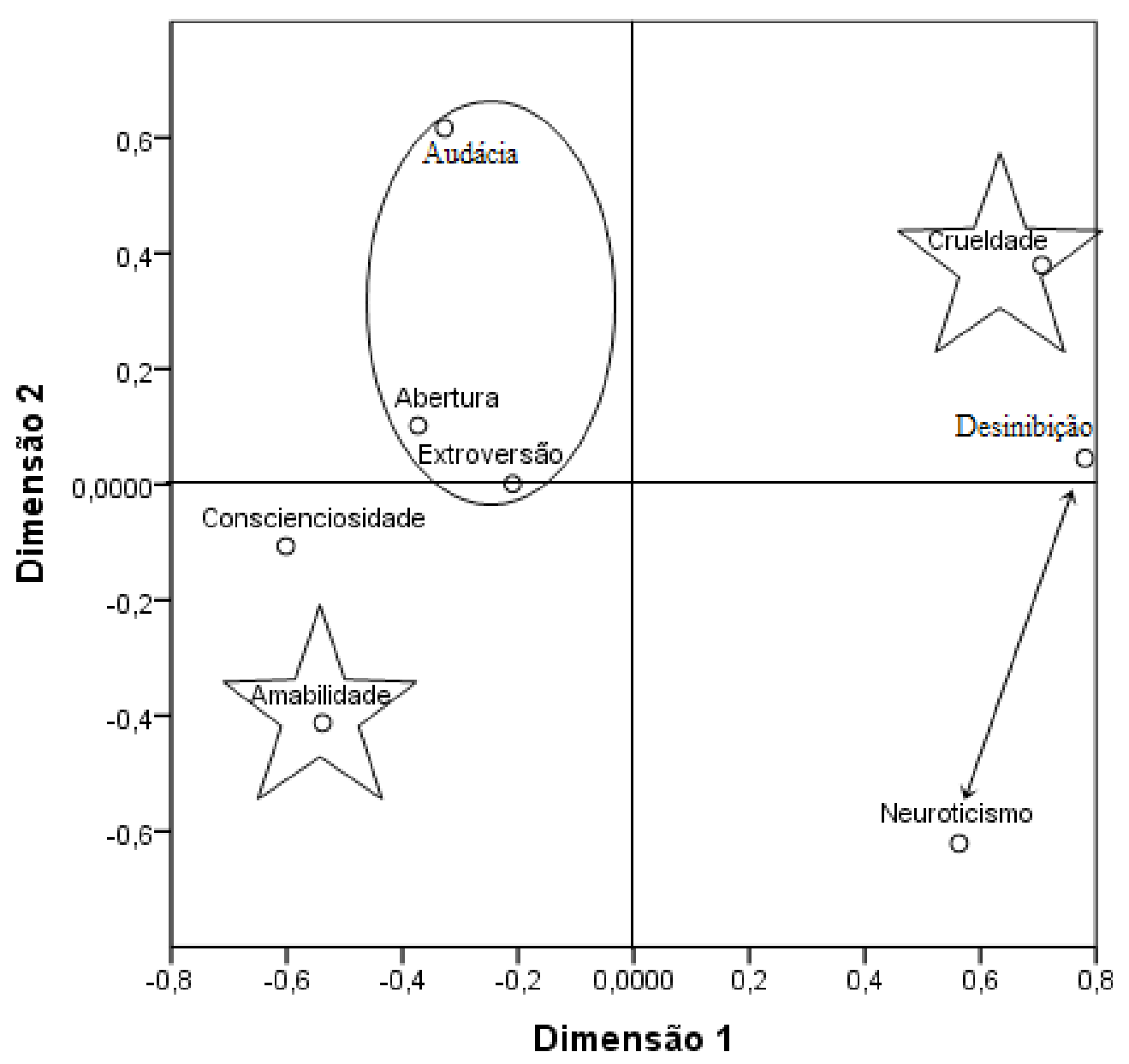

Figura 2. Representação espacial dos fatores de personalidade e dimensões de psicopatia 


\section{DISCUSSÃO}

O presente estudo teve como meta apresentar o procedimento de adaptação linguística da TriPM para o português brasileiro, apresentar dados sobre a consistência interna do instrumento e explorar a relação entre o modelo dos cinco grandes fatores da personalidade com três domínios fenotípicos que compõe a psicopatia (Audácia, Desinibição e Crueldade), segundo o MTP (Patrick et al., 2009). Os achados foram, em maioria, compatíveis com as hipóteses levantadas e com os resultados de estudos prévios (Blagov et al., 2015; Poy et al., 2014; Stanley et al., 2013) deflagrando a psicopatia como um transtorno heterogêneo, inclusive sob a demarcação do modelo dos cinco grandes fatores da personalidade, de modo que o padrão de correlações entre os fatores da TriPM e do CGF apresentam especificidades.

Audácia apresentou um padrão de personalidade claramente adaptativo, marcado por escores mais baixos em neuroticismo e mais altos em extroversão e abertura à mudança. Tais resultados sugerem que pessoas com traços psicopáticos tendem a ser comunicativos, expansivos, sociáveis, loquazes, além de apresentarem um charme superficial (Patrick et al., 2009). Percebe-se, ainda, que as relações negativas com neuroticismo revelam uma faceta da psicopatia que envolve estabilidade emocional, sendo um indicativo de baixa ansiedade, onde pessoas com traços psicopáticos tendem a manter a calma e o foco, mesmo em situações de intenso estresse (Poy et al., 2013; Stanley et al., 2012; Venables et al., 2013). Portanto, estes resultados estão de acordo com o entendimento contemporâneo sobre a psicopatia, que demarca aspectos de ajustamento positivo na caracterização da síndrome (Cleckley, 1976; Patrick et al., 2009).

Desinibição, por sua vez, mostrou um padrão caracterizado por tendências de personalidade associadas à desfechos negativos, como altos escores em neuroticismo e baixos escores em amabilidade e conscienciosidade. Considerando-se que desinibição está intrinsecamente associada à porção impulsivaimprudente do espectro da externalização (Carvalho et al., 2010), os dados ora apresentados corroboram a ideia de que a conduta antissocial - tanto em psicopatas quanto em indivíduos sem esse diagnóstico - está intrinsecamente associada à variáveis individuais que predispõe a irritabilidade e labilidade emocional (alto neuroticismo), a indiferença em relação ao outro e egoísmo (baixa amabilidade) e à insubmissão às regras sociais (baixa conscienciosidade). Nesta direção, tais relações podem auxiliar no entendimento de comportamentos típicos da desinibição, como podem ser as ações impulsivas, irresponsáveis e imprudentes, além da baixa tolerância à frustração, má regulação do afeto e suscetibilidade ao uso nocivo de substâncias (Krueger et al., 2007; Patrick et al., 2009; Venables et al., 2013).

Crueldade deflagrou um padrão mais unidimensional, caracterizado por associações negativas com amabilidade, evidenciando que as disfuncionalidades interpessoais presumidas como componentes da psicopatia (como deficiência em capacidades empáticas) estão associados à desconsideração ao próximo e ao egocentrismo. Os relatados padrões de associação são consistentes com dados específicos da literatura (Krueger et al., 2007; Lynam \& Widiger, 2007; Stanley, Wygant, \& Sellbom, 2013; Sherman, Lynam, \& Heyde, 2014). Portanto, é possível compreender, com base nas correlações negativas com amabilidade, as tendências que pessoas com traços psicopáticos tem para a insensibilidade, frieza emocional, incapacidade de estabelecer laços afetivos duradouros e apego emocional superficial (Sherman et al., 2014; Venables et al., 2013).

Por fim, checou-se em que medida o escore total da TriPM se correlaciona com os cinco grandes fatores da personalidade. A combinação de altos escores em audácia, desinibição e crueldade apresentou correlação negativa e estatisticamente significativa com amabilidade, algo já esperado e consistente com estudos prévios (Blagov et al., 2015; Poy et al., 2013), indicando que baixos escores nesse fator da personalidade pode configurar-se como o aspecto central da psicopatia (Sherman et al., 2014). Ademais, as correlações com os fatores extroversão e abertura a mudança, traçam um perfil que pode ser considerado altamente desejável devido a descrição desses fatores como preditores de socialização, emocionalidade positiva, curiosidade e abertura ao diferente (Gomes \& Golino, 2012; Nunes \& Hutz, 2006; Venables, Hall, \& Patrick, 2013). Neste ponto, é possível fazer um paralelo com a ideia de Cleckley (1976) de que pessoas com traços psicopáticos acentuados, apesar de disfuncionalidades emocionais e interpessoais, produzem uma máscara de sanidade, caracterizado por manifestações comportamentais aparentemente adaptativas e, até mesmo, socialmente desejáveis.

O conjunto dos resultados podem, ainda, ser utilizados como evidências adicionais da pertinência de se utilizar o modelo CGF para descrever parcialmente os transtornos da personalidade (Lynam \& Derefinko, 2006; Mille, 2011; Widiger \& Mullins-Sweatt, 2010). Outro destaque se refere a heterogeneidade dos traços psicopáticos, sendo que indivíduos com traços acentuados podem ter um perfil mais resiliente, 
estável, criativo e extrovertido, desde que apresentem mais audácia e crueldade e menor desinibição. Outros, com escores mais altos em desinibição e crueldade apresentariam uma tendência antissocial mais proeminente, caracterizado por alto grau de irritabilidade e labilidade afetiva (alto neuroticismo).

Portanto, os resultados apresentados vão na mesma direção de estudos prévios, mesmo aqueles que se utilizaram de diferentes medidas de psicopatia e dos traços normais da personalidade, verificando que aspectos como, por exemplo, a baixa amabilidade pode ser um dos componentes da personalidade que estariam mais fortemente relacionados a traços psicopáticos acentuados (Lynam \& Widiger, 2007; Miller \& Lynam, 2014; Poy et al., 2014; Sherman et al., 2014). Logo, os resultados, em maioria, convergem com a literatura, constituindo-se como evidências preliminares de validade convergente da TriPM no contexto brasileiro. Quanto à consistência interna dos fatores, observaramse resultados próximos aos reportados em outros estudos (Blagov et al., 2015; Sellbom \& Philips, 2013), sendo valores considerados aceitáveis para fins de pesquisa (Urbina, 2007; Nunnaly, 1991).

As contribuições advindas desta pesquisa devem ser avaliadas com a cautela devida. Trata-se de um estudo com uma amostra não probabilística de estudantes universitários, o que pode ter imposto restrições quanto à variabilidade na expressão dos domínios da psicopatia. Além disso, destaca-se como potencial limitação o fato de a avaliação da psicopatia ter sido feita com medidas explícitas, tipo lápis e papel. É possível que a tendência que os psicopatas têm para mentir pode se refletir em instrumentos de autorrelato, distorcendo ou enviesando suas respostas; também há que considerar o embotamento emotivo dos psicopatas, incidindo em uma má etiquetagem de suas experiências afetivas, podendo levá-los comumente a relatos imprecisos de suas emoções (Lillienfeld \& Fowler, 2006).

Por fim, em razão do anteriormente comentado, em estudos futuros será importante contar com amostras mais heterogêneas, incluindo pessoas da população geral e amostra em situação prisional. Também será necessário ter em conta a elaboração de uma medida implícita de psicopatia, procedimento que reduz o viés do falseamento de respostas, pois considera o tempo de reação do participante de modo a apreender sua atividade inconsciente, não controlada (Gouveia, Athayde, Mendes, \& Freire, 2012; Greenwald, Mcghee, \& Schwartz, 1998). Ademais, será relevante considerar outros potenciais preditores da psicopatia como, por exemplo, o apego e os valores humanos (Gouveia, Milfont, \& Guerra, 2014).

\section{REFERÊNCIAS}

Andrade, J. M. (2008). Evidências de validade do Inventário dos Cinco Grandes Fatores de Personalidade para o Brasil. Tese de Doutorado. Departamento de Psicologia, Universidade de Brasília, DF.

Blagov, P. S., Patrick, C. J., Oost, K. M., Goodman, J. A., \& Pugh, A. T. (2015). Triarchic Psychopathy Measure: Validity in relation to normal-range traits, personality pathology, and psychological adjustment. Journal of Personality Disorders, 29, 1-11. http://dx.doi.org/10.1521/pedi_2105_29_182

Carvalho, H. W., Jorge, M. R., \& Lara, D. R. (2014). Modelo estrutural de internalização e externalização: emergência, validade e utilidade clínica. Temas em Psicologia, 22, 725-743. http://dx.doi.org/10.9788/TP2014.4-05

Carvalho, H. W., Patrick, C. J., Krueger, R. F., Markon, E. K., \& Pinheiro, A. M. (2010). Validade de construto da versão brasileira do Inventário Espectral de Externalização: Evidências a partir de uma amostra de estudantes universitários. Revista de Psiquiatria Clínica, 37, 206-211. http://dx.doi.org/10.1590/S010160832010000500004

Carvalho, H. W., Pinheiro, A. M. V., Patrick, C. J., Krueger, R. F., \& Markon, K. E. (2007). Tradução, adaptação cultural e análise de consistência interna do Inventário de Externalização. Avaliação Psicológica, 6, $217-27$.

Cleckley, H. (1976). The Mask of Sanity (5th ed.). St. Louis, MO: Mosby.

Decuyper, M., De Pauw, S., De Fruyt, F., De Bolle, M., \& De Clercq, B. (2009). A Meta-Analysis on Psychopathy-, Antisocial PD- and FFM Associations. European Journal of Personality, 23, 531-565. http://dx.doi.org/10.1002/ per.729

Drislane, L. E., Patrick, C. J., \& Arsal, G. (2014). Clarifying the content coverage of differing psychopathy inventories through reference reference to the triarchic psychopathy measure. Psychological Assessment, 26, 350-362. http:// dx.doi.org/10.1037/a0035152

Fowles, D. C., \& Dindo, L. (2006). A Dual-Defict Model of Psychopathy. In C. J. Patrick (Ed.), Handbook of Psychopathy (pp. 14-34). New York: The Guilford Press.

Gomes, C. M. A. \& Golino, H. F. (2012). Relações hierárquicas entre os traços amplos do Big Five. Psicologia: Reflexão \& Crítica, 25, 445-456. http://dx.doi.org/10.1590/s0102-79722012000300004 
Gouveia, V. V., Athayde, R. A. A., Mendes, L. A. C., \& Freire, S. E. A. (2012). Introdução às medidas implícitas: Conceitos, técnicas e contribuições. Revista da Sociedade de Psicologia do Rio Grande do Sul, 12, 80-92.

Gouveia, V. V., Milfont, T. L., \& Guerra, V. M. (2014). Functional theory of human values: Testing its content and structure hypotheses. Personality and Individual Differences, 60, 41-47. http://dx.doi.org/10.1016/j.paid.2013.12.012

Greenwald, A. G., Mcghee, D. E., \& Schwartz, J. K. L. (1998). Measuring individual differences in implicit cognition: The Implicit Association Test. Journal of Personality and Social Psychology, 74, 1464-1480. http://dx.doi. org/10.1037/0022-3514.74.6.1464

Hare, R. D. (2003). The Hare Psychopathy Checklist-Revised. Toronto, ON: Multi-Health Systems.

Hauck Filho, N., Teixeira, M. A. P., \& Almeida, R. M. M. (2014). Estrutura fatorial da Psychopathy Checklist-Revised (PCL-R): Uma revisão sistemática. Avaliação Psicológica, 13, 247-256.

John, O. P., Donahue, E. M., \& Kentle, R. L. (1991). The “Big Five” Inventory \& Versions $4 a$ and 54. Berkeley, University of California. Institute of Personality and Social Research.

Kraepelin, E. (1904). Psychiatrie: Ein lehrbuch. Leipzig: Barth.

Krueger, R. F., Markon, K. E., Patrick, C. J., Benning, S., \& Kramer, M. (2007). Linking anti- social behavior, substance use and personality: towards a comprehensive quantitative model of adult externalizing spectrum. Journal of Abnormal Psychology, 116, 645-666. http://dx.doi.org/10.1037/0021-843X.116.4.645

Krueger, R. F., Markon, K. E., Patrick C. J., \& Iacono, W. G. (2005). Externalizing psychopathology in adulthood: A dimensional-spectrum conceptualization and its implications for DSM-V. Journal Abnormal Psychology, 114, $537-$ 550. http://dx.doi.org/10.1037/0021-843X.114.4.537

Likken D. (2006). Psychopathic Personality: The Scope of the Problem. In C. J. Patrick (Ed.), Handbook of Psychopathy (pp. 3-13). New York: The Guilford Press.

Lillienfeld, S. T. \& Fowler, K. A. (2006). The Self-Report Assessment of Psychopathy: Problems, Pitfalls, and Promises. In C. J. Patrick (Ed.), Handbook of Psychopathy (pp. 107-132). New York: The Guilford Press.

Lillienfeld, S. O. \& Widows, M. R. (2005). Psychopathic Personality Inventory - Revised (PPI-R) professional manual. Odessa, FL: Psychological Assessment Resources.

Lynam, D. R., \& Derefinko, K. J. (2006). Psychopathy and Personality. In C. J. Patrick (Ed.), Handbook of Psychopathy (pp. 133-155). New York: The Guilford Press.

Lynam, D. R., \& Miller, J. D. (2014). Psychopathy from a basic trait perspective: The utility of a five-factor model approach. Journal of Personality. http://dx.doi.org/10.1111/jopy.12132

Lynam, D. R. \& Widiger, T. A. (2007). Using a general model of personality to identify the basic elements of psychopathy. Journal of Personal Disorders, 21, 160-178. http://dx.doi.org/10.1521/pedi.2007.21.2.160

McCrae, R. R., \& John, O. P. (1992). An introduction to the five-factor model and its applications. Journal of Personality, 60, 175-215. http://dx.doi.org/10.1111/j.1467-6494.1992.tb00970.x

McCrae, R. R. (2010). The place of the FFM in personality psychology. Psychological Inquiry. 21, 57-64. http://dx.doi. org/10.1080/10478401003648773

Miller, J. D., \& Lynam, D. R. (2014). Psychopathy and personality: Advances and debates. Journal of Personality. http:// dx.doi.org/10.1111/jopy.12145

Miller, J. D., Hyatt, C. S., Rauscher, S., Maples, J. L., \& Zeichner, A. (2014). A test of the construct validity of the Elemental Psychopathy Assessment scores in a community sample for adults. Psychological Assessment, 26, 555-562. http://dx.doi.org/10.1037/a0035952

Miller, J. D., Watts, A., \& Jones, S. E. (2011). Does psychopathy manifest divergence relations with componentes of its nomological network depending on gender? Personality and Individual Differences, 50, 564-69. http://dx.doi. org/10.1016/j.paid.2010.11.028

Nunnally, J. C. (1991). Teoría psicométrica. México, DF: Trillas.

Nunes, C. H. S. S., \& Hutz, C. S. (2006). Construção e validação de uma escala de extroversão no modelo dos Cinco Grandes Fatores de Personalidade. Psico-USF, 11, 147-155. http://dx.doi.org/10.1590/S1413-82712006000200003

Patrick, C. J. (2006). Back to the Future: Cleckley as Guide to the Next Generation of Psychopathy Research. In C. J. Patrick (Ed.), Handbook of Psychopathy (pp. 605-617). New York: The Guilford Press.

Patrick, C. J. (2010). Operationalizing the Triarchic Conceptualization of Psychopathy: Preliminary Description of Brief Scales for Assessment of Boldness, Meanness, and Disinhibition. Tallahassee: Florida State University.

Patrick, C. J., Fowles, D. C., \& Krueger, R. F. (2009). Triarchic conceptualization of psychopathy: Developmental origins of disinhibition, boldness, and meanness. Development and Psychopatholy, 21, 913-938. http://dx.doi.org/10.1017/ S0954579409000492

Pinel, P. (1962). A treatise on insanity (D. Davis, Trans). New York: Hafner (Original work published 1806).

Potter, S., \& Woodworth, M. (2006). Psychopathy and Aggression. In C. J. Patrick (Ed.), Handbook of Psychopathy (pp. 481-494). New York: The Guilford Press.

Poy, R., Segarra, P., Esteller, À., López, R., \& Moltó, J. (2014). FFM Description of the Triarchic Conceptualization of Psychopathy in Men and Women. Psychological Assessment, 26, 69-76. http://dx.doi.org/10.1037/a0034642 
Schmitt, D. P., Allik, J., McCrae, R. R., Benet-Martinez, V., Alcalay, L., Ault, L. et al. (2007). The geographic distribution of big five personality traits: Patterns and profiles of human self-description across 56 nations. Journal of CrossCultural Psychology, 38, 173-212. http://dx.doi.org/10.1177/0022022106297299

Sherman, E. D., Lynam, D. R., Heyde, B. (2014). Agreeableness accounts for fator structure of the youth psychopathic traits inventory. Journal of Personality Disorders, 28, 262-280. http://dx.doi.org/10.1521/pedi_2013_27_124

Silva, I. B. \& Nakano, T. C. (2011). Modelo dos Cinco Grandes Fatores da Personalidade: Análise de pesquisas. Avaliação Psicológica, 10, 51-62.

Stanley, J. H., Wygant, D. B., \& Sellbom, M. (2013). Elaborating of the construct validity of the triarchic psychopathy measure in a criminal offender sample. Journal of Personality Assessment, 95, 343-350. http://dx.doi.org/10.1080/0 0223891.2012 .735302

Urbina, S. (2007). Fundamentos da Testagem Psicológica. Porto Alegre: Artmed.

Venables, N. C., Hall, J. R., \& Patrick, C. J. (2013). Differentiating psychopathy from antisocial personality disorder: A triarchic model perspective. Psychological Medicine, 9, 1-9. http://dx.doi.org/10.1017/S003329171300161X

Widiger, T. A., \& Mullins-Sweatt, S. N. (2010). Clinical utility of a dimensional model of personality disorder. Professional Psychology: Research and Practice, 41, 488-494. http://dx.doi.org/10.1037/a0021694

\author{
Autores: \\ Renan Pereira Monteiro - Mestre, Universidade Federal da Paraíba. \\ RildÉSIA Silva Veloso Gouveia - Doutora, Centro Universitário de João Pessoa. \\ Christopher J. PATRICK - Doutor em Psicologia, Florida State University. \\ Hudson W. DE CARVALHO - Doutor, Universidade Federal de Pelotas. \\ EMERSON Diógenes MedeIRos - Doutor, Universidade Federal do Piauí. \\ CARlos Eduardo Pimentel - Doutor, Universidade Federal da Paraíba. \\ VAldiney Veloso Gouveia - Doutor, Universidade Federal da Paraíba. \\ Endereço para correspondência: \\ Renan Pereira Monteiro \\ Rua Landoaldo Falcão de Souza, 90 - Bloco F, apto. 202 \\ CEP: 58051-117 João Pessoa, PB, Brasil \\ Recebido em: 12.04 .15 \\ Aceito em: 06.07.15
}

